\title{
Determination of a 15437 bp nucleotide sequence around the inhA gene of Mycobacterium avium and similarity analysis of the products of putative ORFs
}

\author{
Monica Labò, ${ }^{1}$ Laura Gusberti, ${ }^{1}$ Edda De Rossi, ${ }^{1}$ Pietro Speziale ${ }^{2}$ \\ and Giovanna Riccardi ${ }^{1}$
}

Author for correspondence: Giovanna Riccardi. Tel: +39382505 574. Fax: +39382528 496.

e-mail : riccardi@ipvgen.unipv.it

1 Dipartimento di Genetica e Microbiologia, Università di Pavia, via

Abbiategrasso, 207,

27100 Pavia, Italy

2 Dipartimento di Biochimica, Università di Pavia, via Bassi, 21 27100 Pavia, Italy

\begin{abstract}
A 15437 bp region encompassing the inhA locus from the Mycobacterium avium chromosome was cloned and sequenced. From the sequencing data generated and the results of homology searches, the primary structure of this region was determined. This region contains four known genes (acnA, fabG, inhA and hemH) and two genes, invA and invB, whose products display homology with p60 invasion protein of Listeria monocytogenes. Six proteins encoded by putative ORFs contained an RGD motif (often involved in binding to macrophage integrins), while ORF1 and MoxR are probably transcriptional regulators. The rest of the putative products encoded by ORFs in the sequenced region showed little homology with the proteins contained in the databases and were considered to be unknown proteins.
\end{abstract}

Keywords: inv genes, inhA gene, Mycobacterium avium, nucleotide sequence

\section{INTRODUCTION}

Mycobacteria, members of which cause tuberculosis and leprosy, produce cell walls of unusually low permeability which contribute to their resistance to therapeutic agents. Their cell walls contain large amounts of $\mathrm{C}_{60}-\mathrm{C}_{90}$ fatty acids, mycolic acids, that are covalently linked to arabinogalactan. Differences in mycolic acid structure may affect the fluidity and permeability of the bilayer and may explain the different sensitivity levels of various mycobacterial species to lipophilic inhibitors (Liu et al., 1996). There are several indications that some existing antimycobacterial drugs may indeed act on the cell wall biosynthetic pathways (Blanchard, 1996). Identification of the precise targets of such drugs may allow design of novel inhibitors of the same enzyme or of related steps in the same pathway.

Several mechanisms seem to be involved in isoniazid (INH) resistance in Mycobacterium tuberculosis (Deretic et al., 1996). The simplest hypothesis is that the

Abbreviation: INH, isoniazid.

The GenBank accession numbers for the sequences reported in this paper are AF002133 for Mycobacterium avium and AF006054 for Mycobacterium tuberculosis. drug is converted inside the bacterium to an activated form by the catalase-peroxidase enzyme, encoded by the $k a t G$ gene (Zhang et al., 1993), and that the activated drug then inhibits the product of the inhA gene, an enzyme probably involved in mycolic acid biosynthesis (Banerjee et al., 1994). InhA has been shown to catalyse the $\beta$-NADH-specific reduction of 2-trans-enoyl-acyl carrier protein, an essential step in fatty acid elongation (Dessen et al., 1995). The M. tuberculosis inhA gene appears to be in an operon with the gene encoding the $29 \mathrm{kDa}$ ORF that exhibits sequence similarity to several other proteins involved in fatty acid biosynthesis, such as the 3-ketoacyl-acyl carrier protein reductase ( $f a b G$ gene product) from Escherichia coli (Banerjee et al., 1994).

The Mycobacterium avium complex is an intracellular pathogen that predominantly infects and multiplies within macrophages. $M$. avium infections are frequently present in patients with AIDS (Inderlied et al., 1993). Treatment of infections caused by $M$. avium still remains a challenge since these organisms are resistant to the majority of antituberculous drugs, presumably because of their impermeability to these agents. The bacterial cell envelope architecture could act as a barrier to some of the drugs (Brennan \& Nikaido, 1995). While the complex cell wall structure of mycobacteria prob- 
ably confers the permeability barrier that underlies their resistance to many existing antibacterial agents, the same unique structure contains a series of potential targets for novel Mycobacterium-specific inhibitors. The mycolic acids are unique to the mycobacteria and, again, it can be envisaged that their synthesis and assembly into the cell wall entail a series of enzymes, each representing a potentially attractive target for antibacterial action.

Since the inhA gene seems to be directly involved in mycolic acid biosynthesis, we have sequenced and analysed $15437 \mathrm{bp}$ around this region to establish if other related genes are present in M. avium.

\section{METHODS}

Isolation of the inhA locus from a $\lambda$ GEM-11 library of $\boldsymbol{M}$. avium. The Mycobacterium smegmatis inhA gene (kindly provided by Professor W. R. Jacobs, Albert Einstein College of Medicine, NY, USA) was used as probe to screen a $2 \mathrm{GEM}$ 11 library of $M$. avium GIR10 (Milano et al., 1996). Several positive phages were identified and one of them, $\lambda \mathrm{GEM}-33$, was chosen to map the $M$. avium inhA gene. DNA fragments from $\lambda$ GEM-33 were subcloned into pGEM-4Z (Promega) for sequencing.

Procedures such as plaque hybridization and synthesis of radioactive DNA probes with random hexamer primers were carried out using standard protocols (Sambrook et al., 1989).

Genomic and $\lambda$ GEM-33 DNAs were digested with appropriate restriction endonucleases, fractionated on a $1 \%$ agarose gel and transferred to a nylon membrane (Schleicher \& Schuell) according to the manufacturer's instructions. Hybridization was performed at $42{ }^{\circ} \mathrm{C}$ with $50 \%$ formamide; the blot was washed at $60^{\circ} \mathrm{C}$ in $1 \times \mathrm{SSC} / 0 \cdot 1 \%$ SDS.

To isolate and clone the corresponding inv genes from $M$. tuberculosis, we used the homologous PCR product as a probe to screen an M. tuberculosis cosmid library (kindly provided by Dr S. Cole, Institut Pasteur, Paris, France). Several positive cosmids were isolated and the $M$. tuberculosis inv genes were cloned and sequenced by standard procedures.

DNA sequencing and analysis. The $M$. avium DNA fragment from $\lambda \mathrm{GEM}-33$ was digested with several restriction enzymes and the resulting fragments were subcloned into pGEM-4Z. Sequencing was performed by the dideoxy chain-termination method (Sanger et al., 1977), using the Pharmacia T7 Polymerase Sequencing kit according to the supplier's instructions with $\left.{ }^{35} \mathrm{~S}\right] \mathrm{dATP} \alpha \mathrm{S}$. The sequence was determined on both strands and all restriction sites used to subclone into pGEM-4Z were overlapped. The subclones were sequenced using the SP6 and T7 promoter primers for pGEM-4Z as well as synthetic oligonucleotide primers designed from the resulting sequence.

DNA and protein sequences were compared with nonredundant databases at the National Center for Biotechnology Information (NCBI), using the BLAST programs (Altschul et al., 1990, 1994). The putative ORFs were identified both with the NCBI ORF-FINDER and with the PC/GENE programs. Putative ORFs in the region were sought in all six possible translation frames. Further analysis was performed using the PRosite catalogue (Bairoch, 1992). Calculations of the isoelectric point and of the molecular mass were determined by Compute pI/Mw (Bjellquist et al., 1993, 1994). Multiple alignment was performed with the CLUSTAL w program (Thompson et al., 1994).

PCR procedures. DNA for PCR analysis, from different mycobacterial species, was extracted by the following procedure. A loopful of organisms from a colony was suspended in $1 \mathrm{ml} \mathrm{H} \mathrm{H}_{2} \mathrm{O}$ and boiled for $10 \mathrm{~min}$. Samples $(10 \mu \mathrm{l})$ were then used directly in PCR reactions using the primers $5^{\prime}$ GGGGGTGCCGTACTCGTGGGG-3' (upper) and $5^{\prime}$ ACCCGCCCGGGCCGTAGAAG-3' (lower).

\section{RESULTS AND DISCUSSION}

We used the $M$. smegmatis inhA gene (Banerjee et al., 1994) as a probe to isolate the corresponding gene from a $\lambda$ GEM-11 library of M. avium (Milano et al., 1996). Several positive recombinants were selected and one of them ( $\lambda G E M-33)$ was further studied. This recombinant phage carried a total insert of $15437 \mathrm{bp}$ and its physical map is shown in Fig. 1. Hybridization experiments revealed a fragment whose size was consistent with that predicted by the DNA sequence of the $\lambda$-insert (data not shown).

ORFs present in the resultant 15437 bp segment, which has a $G+C$ content of $69 \mathrm{~mol} \%$, typical of $M$. avium, were identified on the basis of their codon usage and database search similarities (Tables 1 and 2). The end points of the ORFs in the sequence, the size of the protein encoded, isoelectric point, putative ShineDalgarno sequence and initiation codon are shown in Table 1. Many of the genes appear to comprise independent monocistronic transcriptional units although there are some discernible operons. Similarities of predicted ORF products with database protein sequences and matches to PROSITE motifs (Table 2) led to the identification of many of the genes and their biological functions.

Of our sequence, $13170 \mathrm{bp}$ in total was found to encode protein. The remaining 2267 bp seems to be non-coding. The largest non-coding stretch, 1506 bp (from nt 3167 to nt 4673), was without apparent structural features, as well as the 644 bp second non-coding stretch.

\section{M. avium inhA gene}

From positions 10566 to 11333 and from 11368 to 12174, we found, respectively, the $f a b G$ and inh $A$ genes, as previously identified in M. tuberculosis (Banerjee et al., 1994). The predicted InhA protein of $M$. avium shows strong sequence similarity $(85.5 \%$ identity in a 269-residue overlap) to the corresponding protein of $M$. tuberculosis. A serine-94 $\rightarrow$ alanine-94 mutation of the inhA gene of $M$. smegmatis and of Mycobacterium bovis has been shown to cause resistance to INH and ethionamide (Banerjee et al., 1994) by decreasing the affinity of the mutant protein for NADH (Dessen et al., 1995). The structure of the NADH binding site of InhA suggests that recognition of $\mathrm{NADH}$ is mediated by interactions with an array of polar amino acids and backbone atoms (Dessen et al., 1995). The residues which are involved in the NADH-binding site of InhA 

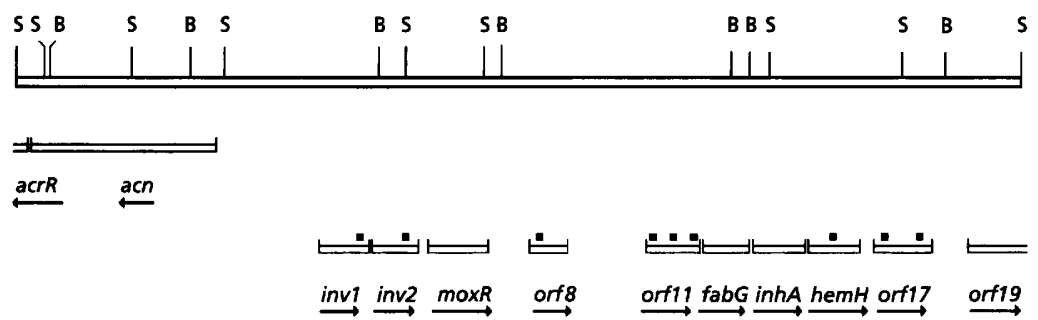

Fig. 1. Restriction map and ORF organization of the $M$. avium chromosome around the inhA gene. B, BamHI restriction sites; S, Sacl restriction sites; $\square$, RGD motif.

Table 1. Putative ORFs and characteristics of their products in the $15437 \mathrm{bp}$ sequence around the inhA gene of the $M$. avium chromosome

\begin{tabular}{|c|c|c|c|c|}
\hline ORF & $\begin{array}{c}\text { End points } \\
\text { (nt) }\end{array}$ & $\begin{array}{l}\text { Molecular } \\
\text { mass (kDa) }\end{array}$ & pI & $\begin{array}{c}\mathrm{SD}^{*} \text { consensus } \\
\text { sequence (upper case) } \\
\text { and initiation codon } \\
\text { (bold) }\end{array}$ \\
\hline orf1 & $246<1$ & Partial & Partial & AtGcccAGctAGATG \\
\hline orf 2 & $3167<282$ & $104 \cdot 0$ & $5 \cdot 2$ & GAccGccGAcGtaATG \\
\hline orf 4 & $4673>5494$ & $28 \cdot 8$ & $9 \cdot 6$ & AGGAcGccGcGGTG \\
\hline orf5 & $5520>6254$ & $25 \cdot 4$ & $9 \cdot 6$ & AAcGAGGAGccATG \\
\hline orf6 & $6376>7305$ & $34 \cdot 2$ & $10 \cdot 9$ & GGAGGGttAtcGATG \\
\hline orf 8 & $7949>8458$ & $18 \cdot 6$ & $10 \cdot 7$ & AAcGGcGccAccATG \\
\hline orf9 & $8466>9473$ & $36 \cdot 0$ & $9 \cdot 4$ & GActcGAAtATG \\
\hline orf10 & $10626<9586$ & $39 \cdot 5$ & $10 \cdot 3$ & GGGAGAcGAATG \\
\hline orf11 & $9733>10569$ & $30 \cdot 6$ & $11 \cdot 5$ & AGcGGctcGcccGATG \\
\hline orf12 & $11414<10509$ & $30 \cdot 8$ & $5 \cdot 4$ & GAcGAGtcGGtGATG \\
\hline orf13 & $10566>11333$ & $26 \cdot 7$ & $5 \cdot 6$ & AGGttGAcGGGGTG \\
\hline orf14 & $11368>12174$ & $28 \cdot 5$ & $5 \cdot 0$ & AAGGAcGGAcATG \\
\hline orf15 & $12182>13189$ & $29 \cdot 8$ & $11 \cdot 8$ & AGAcGGGcAATG \\
\hline orf16 & $13193<14155$ & $33 \cdot 4$ & $5 \cdot 5$ & cAAGAAtAcGcGTG \\
\hline orf17 & $13211>14128$ & $33 \cdot 7$ & $11 \cdot 9$ & AGGcGGAATG \\
\hline orf18 & $14171>14608$ & $15 \cdot 6$ & $5 \cdot 6$ & ttcttgecgcATG \\
\hline orf19 & $14639>15437$ & Partial & Partial & AAAGGAAttccAATG \\
\hline
\end{tabular}

* SD, Shine-Dalgarno.

from $M$. tuberculosis wild-type are unchanged in the $M$. avium InhA sequence; this finding rules out a possible involvement of $M$. avium InhA in the natural resistance of the micro-organism to INH.

In $M$. avium and in M. tuberculosis DNA, the noncoding region between the two ORFs is short and may lack a promoter; consequently, the two genes may be organized in an operon. Immediately downstream of the inhA gene (from nt 12182 to nt 13189) there is orf15, whose gene product shows similarity with several ferrochelatase enzymes. The last step in haem synthesis is the insertion of iron into the ring of protoporphyrin IX. The enzyme which catalyses this reaction is a ferrochelatase, encoded by the Rhodobacter capsulatus hemH gene (Kanazireva \& Biel, 1995). The degree of sequence homology of $M$. avium ORF15 compared with human ferrochelatase (Crouse et al., 1996) is $34 \%$ identity in a 132-residue overlap. The same gene organization is present in M. tuberculosis (accession no.
gnl/Z79701) and the fabG-inhA-hemH genes could be organized in an operon in both micro-organisms (Fig. 2).

\section{invA and invB genes}

Little is known about the bacterial factors that enable pathogenic mycobacteria to survive and multiply within the macrophages of the infected host. M. tuberculosis bacilli are thought to enter the macrophage via specific binding to complement receptors and the macrophage mannose receptor (Fenton \& Vermeulen, 1996). The neural tropism of Mycobacterium leprae has been ascribed to the specific binding of $M$. leprae to the laminin- $\alpha_{2}\left(\mathrm{LN}-\alpha_{2}\right)$ chain on Schwann cell axon units. It has been suggested that $M$. leprae interacts with cells by binding to $\beta_{4}$ integrin via an $\mathrm{LN}-\alpha_{2} \mathrm{G}$ bridge (Rambukkana et al., 1997). Recently, it has been demonstrated that the $M$. avium $68 \mathrm{kDa}$ protein mediates attachment of $M$. avium to macrophages, by interacting with $\alpha_{v} \beta_{3}$ on these cells (Hayashi et al., 1997). 
Table 2. Similarity of the putative products of ORFs identified on $\lambda$ GEM-33 M. avium insert

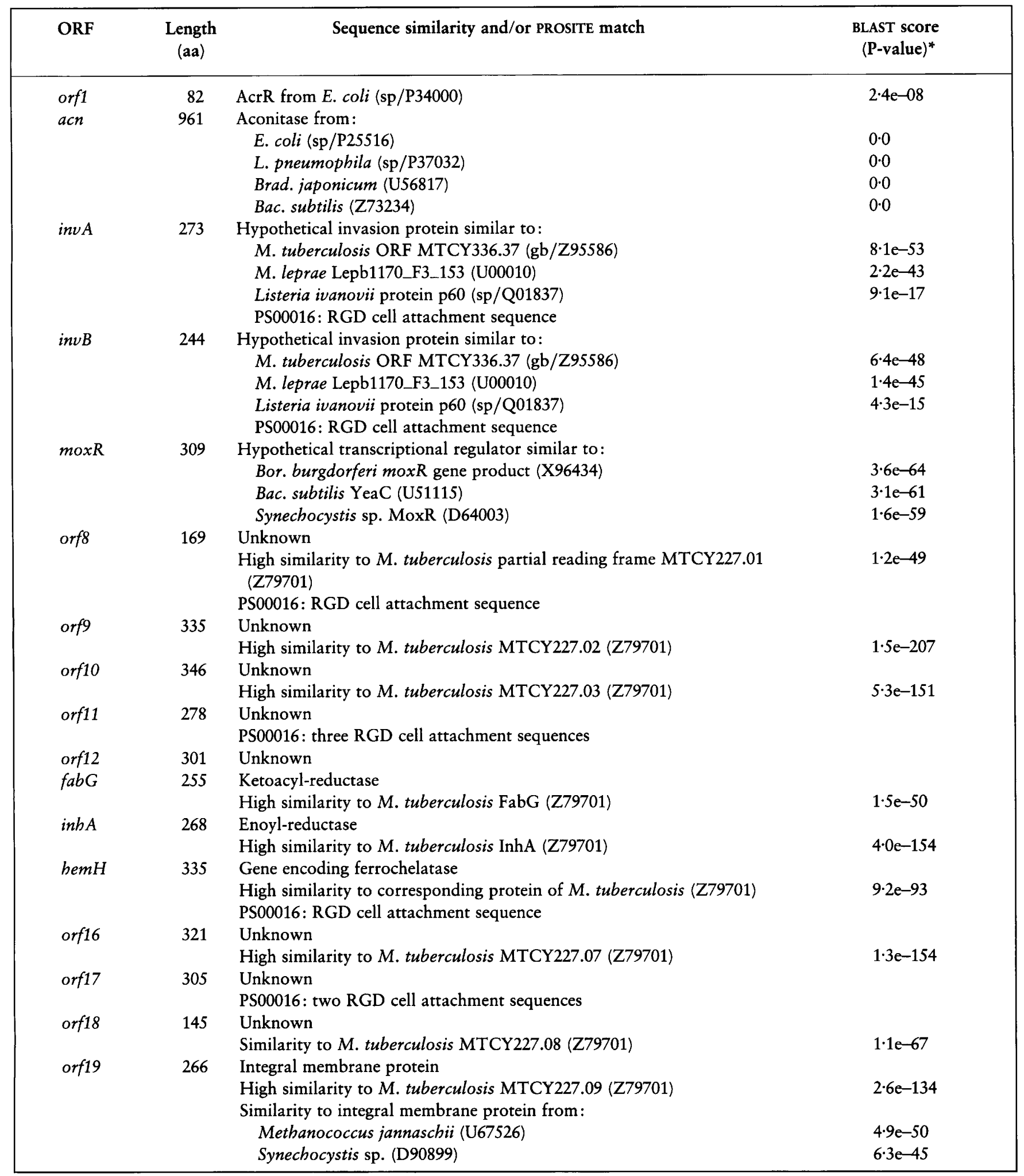

* The P-value, calculated with the BLAST program, represents the probability that two proteins are related. The lower the P-value, the greater the degree of similarity. 


\section{M. avium}

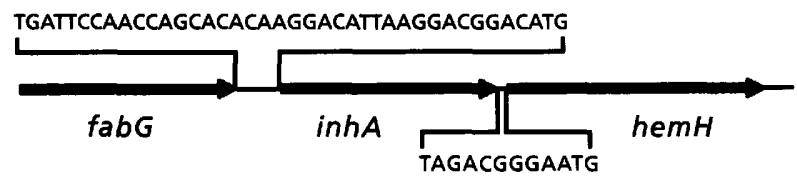

M. tuberculosis

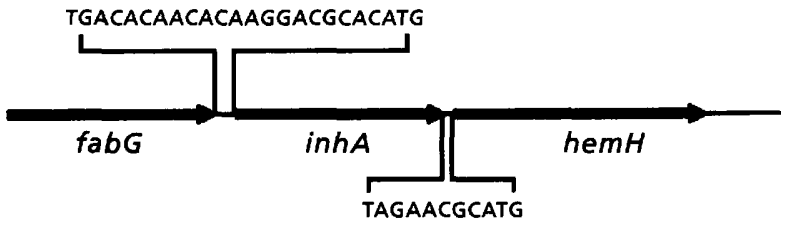

Fig. 2. Physical organization of fabG-inhA-hemH in $M$. avium and $M$. tuberculosis.

orf4 (from nt 4673 to nt 5494) and orf5 (from nt 5520 to nt 6254) show a low but detectable level of homology with $\mathrm{p} 60$, a protein that is involved in the uptake of Listeria monocytogenes by non-professional phagocytic cells (Bubert et al., 1992), and that is probably essential for survival inside the phagosome (Bhunia, 1997). Further, p60 is a murein hydrolase that is secreted into the host cell cytosol, where it is degraded by proteasomes (Sijts et al., 1997). The P-values for ORF4 and ORF5 compared with the p60 protein were $9 \cdot 1 \mathrm{e}-17$ and $4 \cdot 3 \mathrm{e}-15$, respectively. The highest score, $8 \cdot 1 \mathrm{e}-53$ for ORF4 and $6.4 \mathrm{e}-48$ for ORF5, was observed with the ORF MTCY336.37 from M. tuberculosis (accession no. $\mathrm{gb} / \mathrm{Z95586)}$. Similar scores, $2 \cdot 2 \mathrm{e}-43$ for ORF4 and $1.4 \mathrm{e}-45$ for ORF5, were with Lepb1170_F3_153 from $M$. leprae (accession no. gi/U00010). As $M$. avium ORF4 and ORF5 show homology with p60, have an RGD motif and are $59.4 \%$ identical in a 219 -residue overlap, we decided to name the corresponding genes inv $A$ and invB, respectively. These genes appear to be in an operon as they are separated by only $26 \mathrm{bp}$.
To evaluate the presence of inv genes within the mycobacterial genus, we used PCR, utilizing the upper and lower primers (see Methods) from M. avium invB. As shown in Fig. 3, a band of amplified DNA, with the appropriate size, appeared in all mycobacteria strains tested. This result is not surprising since, for example, the iap gene (encoding p60) has been found in several tested Listeria spp. (pathogenic and non-pathogenic) (Kohler et al., 1990).

The M. tuberculosis PCR product was used as a probe to screen a corresponding cosmid library. The isolated M. tuberculosis clone was mapped and $2360 \mathrm{bp}$ was sequenced. Sequence analysis revealed the presence of two M. tuberculosis inv genes and a physical organization very similar to that of $M$. avium (data not shown).

Fig. 4 shows the alignment of amino acid sequences of $M$. avium InvA, $M$. avium InvB, $M$. tuberculosis InvA, $M$. tuberculosis InvB, M. leprae Inv, M. tuberculosis ORF MTCY336.37 and C-terminal L. monocytogenes p60. As shown in Fig. 4, several amino acid blocks are conserved between Inv proteins and p60 at the Cterminal domain. It has been demonstrated that the p 60 cysteine residue at position 39 is essential for the hydrolytic activity of the protein (Wuenscher et al., 1993). The same residue is conserved in M. avium and M. tuberculosis Inv proteins. As shown in Fig. 4, five proteins contain an RGD motif, which is common to many extracellular proteins and which is thought to play a key role in cell adhesion (Rouslahti \& Pierschbacher, 1986, 1987). RGD sequences have also been identified in bacterial proteins and have been shown to interact with host receptors (Frankel et al., 1996; Everest et al., 1996). However, non-RGD-mediated interactions between bacterial ligands and their host cell integrin receptors have also been reported (Leong et al., 1990). Whether the M. avium and M. tuberculosis Inv proteins are really involved in adhesion-invasion processes remains to be determined.

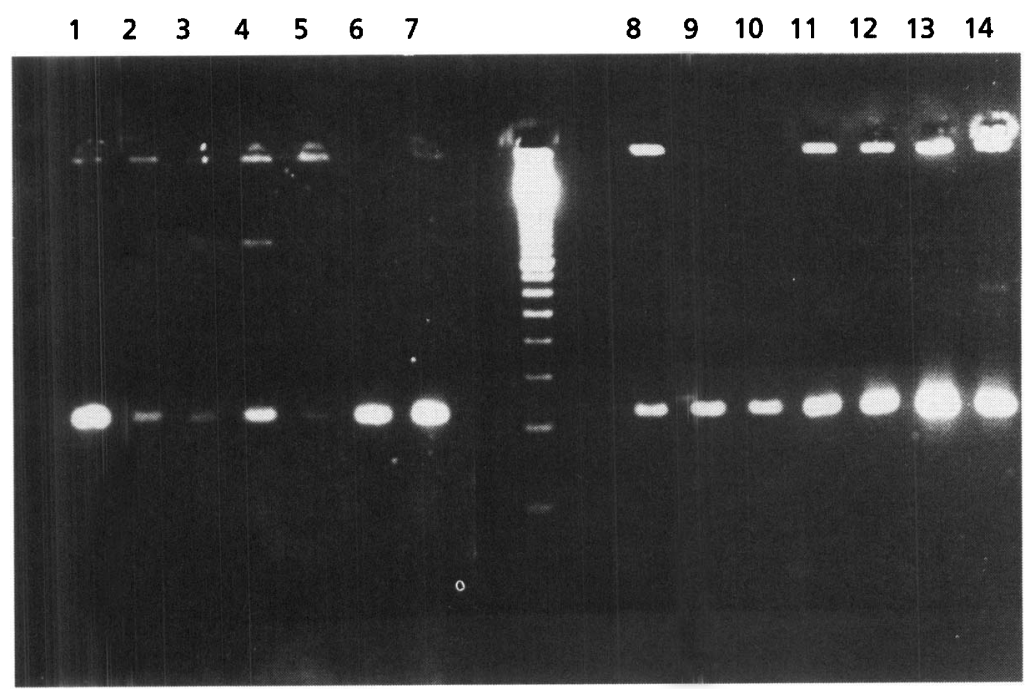

Fig. 3. Detection by PCR of the inv genes from mycobacterial species. Lanes: $1, M$. simiae; $2, M$. chelonae; $3, M$. gordonae; 4 , $M$. marinum; $5, M$. bovis BCG; $6, M$. flavescens; $7, M$. fortuitum; $8, M$. kansasii; 9 , $M$. xenopi; $10, M$. terrae; $11, M$. smegmatis; $12, M$. abcessus; $13, M$. avium; and $14, M$. tuberculosis H37Rv. The fainter PCR amplification product observed in $M$. bovis BCG was due to the quality of the sample, and was brighter in other experiments. 


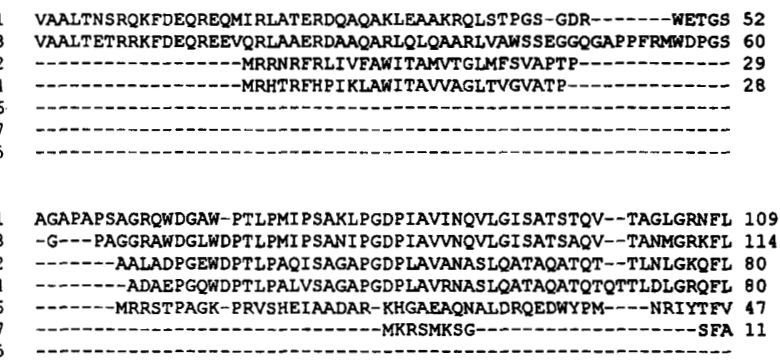

OOLGILKPDD--TGITNAAPGGVGARIPRVYGROATEYVIRRGMSOIGVPYSWGGGNAAG 167 EQLGILQPTD--TGITN-APAGSAGRI PRVYGRQASEYVIRRGMSOIGVPYSWGGGN-AG 170 GGLGINLGGNDAPAAAATP-SNPGGKI PRVYGROAIEYVIKRMGSOMGVPYSWGGGSLDG 139 GGLGINLGG---PAASGPSRATT GAS I PRAKRROAVEYVIRRAGSOMGVPYSWGGGSITG 137 TGYAMLVTS--IITCS-LAYADSGTRT--ADYOOYIDTVVORAIAORGVPFSWAGGGVSG 137 TGLAMLVTS-IGLAMMLAP--MVAAPGLAAADPATRP--VDYQQITDVIIARGLSQRGVPFSWAGGGISG 67
-1

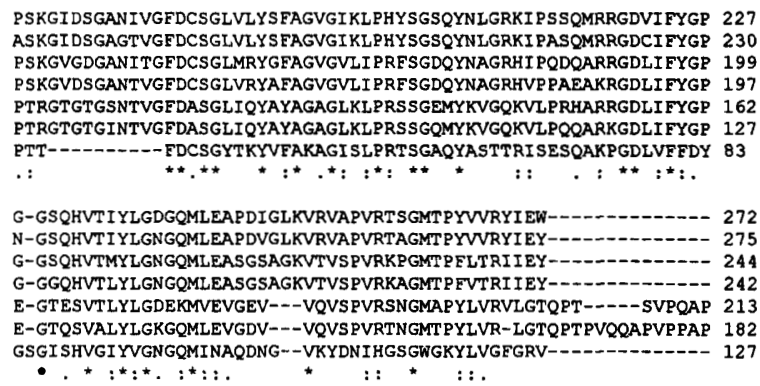

Fig. 4. Comparison of the predicted amino acid sequences of the $M$. avium InvA (1) and InvB (2) with the sequence of $M$. leprae Inv (6), M. tuberculosis InvA (3), InvB (4) and ORF MTCY336.37 (7) and C-terminal L. monocytogenes p60 (5). Asterisks indicate amino acid identity, colons indicate conservative amino acid substitution, and stops indicate that four out of seven proteins have the same amino acid residue.

The degree of sequence homology of $M$. avium InvA compared with that of $M$. tuberculosis InvA and $M$. leprae Inv is, respectively, $72.6 \%$ identity (in a 277 residue overlap) and $49.6 \%$ identity (in a 131-residue overlap). The degree of sequence homology of M. avium InvB compared with that of $M$. tuberculosis InvB and M. leprae Inv is, respectively, $76 \%$ identity (in a $246-$ residue overlap) and $48.9 \%$ identity (in a 131-residue overlap). Furthermore, the amino acid sequences of $M$. avium InvA and InvB, compared with $M$. tuberculosis ORF MTCY336.37, are $55.7 \%$ and $52.7 \%$ identical, in a 131-residues overlap, respectively. Despite the $M$. leprae gene name, the corresponding protein is much closer to M. tuberculosis ORF MTCY336.37 than to Inv proteins. The degree of sequence homology of $M$. leprae Inv compared with that of $M$. tuberculosis ORF MTCY336.37 is $70 \%$ (in a 197-residue overlap). The gene organization around the $M$. leprae inv gene is strikingly different from that of $M$. avium inv genes and is much closer to that of $M$. tuberculosis orf MTCY336.37, suggesting that the $M$. leprae and $M$. tuberculosis genes are homologues. This would also explain the lack of a downstream homologue of $M$. leprae Lepb1170_F3_153. A striking feature of ORF MTCY336.37 is a domain consisting of eight QQAPV repeats in the $\mathrm{C}$-terminal region.

We also analysed M. avium InvA and InvB for potential membrane proteins. For this purpose, the amino acid sequences were scanned with TMbase (Hofmann \& Stoffel, 1993). The results indicated two strong transmembrane helices for InvA and one strong transmembrane helix for InvB (data not shown).

There is an immediate need to understand the molecular basis of virulence and the pathogenesis of M. tuberculosis before the current molecular biological and immunological tools can be used in the prevention and control of the disease. Pathogens entering the human body must quickly adapt to changes in temperature, $\mathrm{pH}$, osmotic strength, oxygen availability and nutrient concentration. Successful pathogens have evolved the ability to regulate expression of virulence genes.

invA/invB gene expression has been exploited in $M$. tuberculosis extracellular and intracellular growth. From preliminary data, it seems that $M$. tuberculosis $i n v B$ expression is induced only in response to growth within the macrophage (unpublished data). Other experiments are in progress to evaluate the function of InvA and InvB in mycobacterial pathogenesis.

Downstream of M. avium orf5 (invA) is orf6 (from nt 6376 to nt 7305 ), whose product showed high similarity to MoxR of Borrelia burgdorferi (P-value $3 \cdot 6 \mathrm{e}-64$; accession no. gi/X96434), MoxR of Synechocystis sp. (P-value 1.6e-59; accession no. gi/D64003) and $\mathrm{YeaC}$ of Bacillus subtilis (P-value $3 \cdot 1 \mathrm{e}-61$; accession no. gi/U51115). MoxR seems to be involved in the regulation of formation of active methanol dehydrogenase in Paracoccus denitrificans (van Spanning et al., 1991). Another transcriptional regulator could be ORF1, whose 82 amino acids showed similarity (35.6\% identity in a 59-residue overlap) to $E$. coli AcrR, a repressor that plays a modulating role in the regulation of $a c r A B$ genes of E. coli (Ma et al., 1996).

\section{Aconitase}

Aconitases are monomeric proteins containing single labile $[4 \mathrm{Fe}-4 \mathrm{~S}]$ clusters that possess a versatile molecular structure adapted to catalyse reactions with citrate, isopropylmalate and homocitrate and to function as iron-responsive regulators of mRNA translation or stability (Klausner \& Rouault, 1993; Rouault \& Klausner, 1996; Hentze \& Kuhn, 1996). Crystallographic studies with porcine-heart mitochondrial aconitase have revealed the presence of three structural domains $(1,2$ and 3) tightly packed around the $[\mathrm{Fe}-\mathrm{S}]$ cluster and a fourth domain (4) that is connected by a long linker peptide in such a way as to create a deep active-site cleft (Robbins \& Stout, 1989). This arrangement provides the 
structural prototype for the aconitase family (Gruer $e t$ al., 1997a).

Only a few bacterial aconitases have been studied so far. Two distinct aconitases, AcnA and AcnB, were discovered in E. coli. AcnB is the major citric acid cycle enzyme, subjected to anaerobic and catabolite repression, whereas AcnA is induced by redox stress and by the presence of iron (Prodromou et al., 1991; Bradbury et al., 1996). Aconitase has also been characterized in Bac. subtilis (Dingman \& Sonenshein, 1987), Legionella pneumophila (Mengaud \& Horwitz, 1993) and Bradyrhizobium japonicum (Thony-Meyer \& Kunzler, 1996). E. coli, L. pneumophila and Bac. subtilis AcnA proteins, together with the iron-regulatory proteins and plant aconitases, form an iron-regulatory protein/AcnA subfamily whose members are more closely related to each other than to any other members of the aconitase protein family (Gruer et al., 1997b).

M. avium orf2 starts at position 3167 (complementary strand) with an ATG codon that is preceded by a Shine-Dalgarno-like sequence $\left(5^{\prime}\right.$-CGACG-3') at a distance of $7 \mathrm{nt}$ and ends at position 282 with a TGA stop codon. The derived polypeptide has a predicted molecular mass of $104 \mathrm{kDa}$ and an isoelectric point of $5 \cdot 27$. The deduced amino acid sequence shows high similarity with E. coli aconitase AcnA ( $80 \%$ similarity, $54.1 \%$ identity) as well as with the bacterial aconitases from $L$. pneumophila, Brad. japonicum and Bac. subtilis. The similarity between the M. avium and Cucurbita maxima (pumpkin seed) aconitases (Hayashi et al., 1995) was in the range of $76.7 \%(47.6 \%$ identity). By contrast, $M$. avium aconitase is less related $(34.6 \%$ identity) to porcine mitochondrial aconitase (Zheng et al., 1990). A good degree of similarity was also observed with eukaryotic iron-response-element-binding proteins ( $\mathrm{P}$ value $5 \mathrm{e}-305)$.

It is noteworthy that the cytoplasmic aconitase holoenzyme containing the $[\mathrm{Fe}-\mathrm{S}]$ cluster is in equilibrium with its apoprotein, the iron-response-element-binding protein, which has a regulatory function in iron transport and storage. Hence the function of this protein depends on the availability of intracellular iron for the formation of the $[\mathrm{Fe}-\mathrm{S}]$ cofactor (Klausner \& Rouault, 1993). Crystallographic structure analysis and mutational analysis have led to the identification of 23 residues contributing to the active site (Lauble et al., 1992; Zheng et al., 1992). The 23 residues, which are involved in substrate recognition, $[\mathrm{Fe}-\mathrm{S}]$ cluster ligation and interaction, catalysis or hydrogen binding that support the active-site side chains are also present in the M. avium AcnA sequence (data not shown).

\section{ACKNOWLEDGEMENTS}

This work was supported by a grant from the Istituto Superiore di Sanità, Progetto AIDS-1996, N. 940429, Roma.

We thank S. T. Cole for providing the M. tuberculosis cosmid library and for critical reading of the manuscript. We also thank W. R. Jacobs for providing the inhA probe.

\section{REFERENCES}

Altschul, S. F., Gish, W., Miller, W., Myers, E. W. \& Lipman, D. J. (1990). Basic local alignment search tool. J Mol Biol 215, 403-410.

Altschul, S. F., Boguski, M. S., Gish, W. \& Wooton, J. C. (1994). Issues in searching molecular sequence databases. Nat Genet 6, 119-129.

Bairoch, A. (1992). PROSITE: a dictionary of sites and patterns in proteins. Nucleic Acids Res 20, 2013-2018.

Banerjee, A., Dubnau, E., Quemard, A., Balasubramanian, V., Sun Um, K., Wilson, T., Collins, D., de Lisle, G. \& Jacobs, W. R., Jr (1994). inhA, a gene encoding a target for isoniazid and ethionamide in Mycobacterium tuberculosis. Science 263, 227230.

Bhunia, A. K. (1997). Antibodies to Listeria monocytogenes. Crit Rev Microbiol 23, 77-107.

Bjellqvist, B., Hughes, G. J., Pasquali, C., Paquet, N., Ravier, F., Sanchez, J.-C., Frutiger, S. \& Hochstrasser, D. F. (1993). The focusing positions of polypeptides in immobilized $\mathrm{pH}$ gradients can be predicted from their amino acid sequences. Electrophoresis 14, 1023-1031.

Bjellqvist, B., Basse, B., Olsen, E. \& Celis, J. E. (1994). Reference points for comparisons of two-dimensional maps of proteins from different human cell types defined in a $\mathrm{pH}$ scale where isoelectric points correlate with polypeptide compositions. Electrophoresis 15, 529-539.

Blanchard, J. S. (1996). Molecular mechanisms of drug resistance in Mycobacterium tuberculosis. Annu Rev Biochem 65, 215-239.

Bradbury, A., Gruer, M. J., Rudd, K. E. \& Guest, J. R. (1996). The second aconitase (AcnB) of Escherichia coli. Microbiology 142, $389-400$.

Brennan, P. J. \& Nikaido, H. (1995). The envelope of mycobacteria. Annu Rev Biochem 64, 29-63.

Bubert, A., Kuhn, M., Goebel, W. \& Kohler, S. (1992). Structural and functional properties of the p60 proteins from different Listeria species. J Bacteriol 174, 8166-8171.

Crouse, B. R., Sellers, V. M., Finnegan, M. G., Dailey, H. A. \& Johnson, M. K. (1996). Site-directed mutagenesis and spectroscopic characterization of human ferrochelatase: identification of residues coordinating the $[2 \mathrm{Fe}-2 \mathrm{~S}]$ cluster. Biochemistry 35, 16222-16229.

Deretic, V., Pagan-Ramos, E., Zhang, Y., Dhandayuthapani, S. \& Via, L. E. (1996). The extreme sensitivity of Mycobacterium tuberculosis to the front-line antituberculosis drug isoniazid. Nat Biotechnol 14, 1557-1561.

Dessen, A., Quemard, A., Blanchard, J. S., Jacobs, W. R., Jr \& Sacchettini, J. C. (1995). Crystal structure and function of the isoniazid target of Mycobacterium tuberculosis. Science 227, 1638-1641.

Dingman, D.W. \& Sonenshein, A. L. (1987). Purification of aconitase from Bacillus subtilis and correlation of its $\mathrm{N}$-terminal amino acid sequence with the sequence of the cit $B$ gene. $J$ Bacteriol 169, 3068-3075.

Everest, P., Li, J., Douce, G., Charles, I., De Azavedo, J., Chatfield, S., Dougan, G. \& Roberts, M. (1996). Role of the Bordetella pertussis P.69/pertactin protein and the P.69/pertactin RGD motif in the adherence to and invasion of mammalian cells. Microbiology 142, 3261-3268.

Fenton, M. J. \& Vermeulen, M. W. (1996). Immunopathology of tuberculosis: roles of macrophages and monocytes. Infect Immun 64, 683-690.

Frankel, G., Hershkoviz, R., Mould, A. P., Kachalsky, S. G., Candy, 
D. C. A., Cahalon, L., Humphries, M. J. \& Dougan, G. (1996). The cell-binding domain of intimin from enteropathogenic Escherichia coli binds to $\beta_{1}$ integrins. J Biol Chem 271, 20359-20364.

Gruer, M. J., Artymiuk, P. J. \& Guest, J. R. (1997a). The aconitase family: three structural variations on a common theme. Trends Biochem Sci 22, 3-6.

Gruer, M. J., Bradbury, A. J. \& Guest, J. R. (1997b). Construction and properties of aconitase mutants of Escherichia coli. Microbiology 143, 1837-1846.

Hayashi, M., De Bellis, L., Alpi, A. \& Nishimura, M. (1995). Cytosolic aconitase participates in the glyoxylate cycle in etiolated pumpkin cotyledons. Plant Cell Physiol 36, 669-680.

Hayashi, T., Rao, P. \& Catanzaro, A. (1997). Binding of the 68kilodalton protein of Mycobacterium avium to $\alpha_{\mathrm{v}} \beta_{3}$-on human monocyte-derived macrophages enhances complement receptor type 3 expression. Infect Immun 65, 1211-1216.

Hentze, M. W. \& Kuhn, L. C. (1996). Molecular control of vertebrate iron metabolism: mRNA-based regulatory controls operated by iron, nitric oxide and oxidative stress. Proc Natl Acad Sci USA 93, 8175-8182.

Hofmann, K. \& Stoffel, W. (1993). TMbase - a database of membrane spanning proteins segments. Biol Chem Hoppe-Seyler 347, 166.

Inderlied, C. B., Kemper, C. A. \& Bermudez, L. E. M. (1993). The Mycobacterium avium complex. Clin Microbiol Rev 6, 266-310.

Kanazireva, E. \& Biel, A. J. (1995). Cloning and overexpression of the Rhodobacter capsulatus bemH gene. J Bacteriol 177, 6693-6694.

Klausner, R. D. \& Rouault, T. A. (1993). A double life: cytosolic aconitase as a regulatory RNA binding protein. Mol Biol Cell 4, $1-5$.

Kohler, S., Leimeister-Wachter, M., Chakraborty, T., Lottspeich, F. \& Goebel, W. (1990). The gene coding for protein p60 of Listeria monocytogenes and its use as a specific probe for Listeria monocytogenes. Infect Immun 58, 1943-1950.

Lauble, H., Kennedy, M. C., Beinert, H. \& Stout, C. D. (1992). Structure of activated aconitase : formation of the $[4 \mathrm{Fe}-4 \mathrm{~S}]$ cluster in the crystal. Biochemistry 31, 2735-2748.

Leong, J. M., Fournier, R. S. \& Isberg, R. R. (1990). Identification of the integrin binding domain of the Yersinia pseudotuberculosis invasin protein. EMBO J 9, 1979-1989.

Liu, J., Barry, C. E., III, Besra, G. S. \& Nikaido, H. (1996). Mycolic acid structure determines the fluidity of the mycobacterial cell wall. J Biol Chem 271, 29545-29551.

Ma, D., Alberti, M., Lynch, C., Nikaido, H. \& Hearst, J. E. (1996). The local repressor AcrR plays a modulating role in the regulation of $a c r A B$ genes of Escherichia coli by global stress signals. Mol Microbiol 19, 101-112.

Mengaud, J. M. \& Horwitz, M. A. (1993). The major ironcontaining protein of Legionella pneumophila is an aconitase homologous with the human iron-responsive element-binding protein. J Bacteriol 175, 5666-5676.

Milano, A., De Rossi, E., Gusberti, L., Heym, B., Marone, P. \& Riccardi, G. (1996). The katE gene, which encodes the catalase HPII of Mycobacterium avium. Mol Microbiol 19, 113-123.
Prodromou, C., Haynes, M. J. \& Guest, J. R. (1991). The aconitase of Escherichia coli: purification of the enzyme and molecular cloning and map location of the gene (acn). J Gen Microbiol 137, 2505-2515.

Rambukkana, A., Salzer, J. L., Yurchenco, P. D. \& Tuomanen, E. I. (1997). Neural targeting of Mycobacterium leprae mediated by the $G$ domain of the laminin- $\alpha_{2}$ chain. Cell 88, 811-821.

Robbins, A. H. \& Stout, C. D. (1989). The structure of aconitase. Proteins 5, 289-312.

Rouault, T. A. \& Klausner, R. D. (1996). Iron-sulfur clusters as biosensors of oxidants and iron. Trends Biochem Sci 21, 174-177.

Rouslahti, E. \& Pierschbacher, M. D. (1986). Arg-Gly-Asp: a versatile cell recognition signal. Cell 44, 517-518.

Rouslahti, E. \& Pierschbacher, M. D. (1987). New perspectives in cell adhesion: RGD and integrins. Science 238, 491-497.

Sambrook, J., Fritsch, E. F. \& Maniatis, T. (1989). Molecular Cloning: a Laboratory Manual, 2nd edn. Cold Spring Harbor, NY: Cold Spring Harbor Laboratory.

Sanger, F., Nicklen, S. \& Coulson, A. R. (1977). DNA sequencing with chain-terminating inhibitors. Proc Natl Acad Sci USA 74, 5463-5467.

Sijts, A. J. A. M., Pilip, I. \& Pamer, E. G. (1997). The Listeria monocytogenes-secreted $\mathrm{p} 60$ is an $\mathrm{N}$-end rule substrate in the cytosol of infected cells. J Biol Chem 272, 19261-19268.

van Spanning, R. J., Wansell, C. W., De Boer, T., Hazelaar, M. J., Anazawa, H., Harms, N., Oltmann, L. F. \& Stouthamer, A. H. (1991). Isolation and characterization of the moxJ, moxG, moxI, and moxR genes of Paracoccus denitrificans: inactivation of $\operatorname{mox} J, \operatorname{mox} G$, and $\operatorname{mox} R$ and the resultant effect on methylotrophic growth. J Bacteriol 173, 6948-6961.

Thompson, J. D., Higgins, D. G. \& Gibson, T. J. (1994). Clustal w : improving the sensitivity of progressive multiple sequence alignment through sequence weighting, positions-specific gap penalties and weight matrix choice. Nucleic Acids Res 22, 4673-4680.

Thony-Meyer, L. \& Kunzler, P. (1996). The Bradyrbizobium japonicum aconitase gene (acnA) is important for free-living growth but not for an effective root nodule symbiosis. J Bacteriol $178,6166-6172$.

Wuenscher, M. D., Kohler, S., Bubert, A., Gerike, U. \& Goebel, W. (1993). The iap gene of Listeria monocytogenes is essential for cell viability, and its gene product, p60, has bacteriolytic activity. $J$ Bacteriol 175, 3491-3501.

Zhang, Y., Garbe, T. \& Young, D. (1993). Transformation with kat $G$ restores isoniazid-sensitivity in $M y$ cobacterium tuberculosis isolates resistant to a range of drug concentrations. Mol Microbiol $8,521-524$.

Zheng, L., Andrews, P. C., Hermodson, M. A., Dixon, J. E. \& Zalkin, H. (1990). Cloning and structural characterization of porcine heart aconitase. J Biol Chem 265, 2814-2821.

Zheng, L., Kennedy, M. C., Beinert, H. \& Zalkin, H. (1992). Mutational analysis of active site residues in pig heart aconitase. J Biol Chem 267, 7895-7903.

Received 21 July 1997; revised 1 November 1997; accepted 19 November 1997. 